\title{
Fatores associados à resistência à insulina em populações rurais
}

\author{
Factors associated with insulin resistence in rural populations
}

Larissa Loures Mendes' ${ }^{1}$ Andréa Gazzinelli', Gustavo Velásquez-Meléndez'

\section{RESUMO}

O objetivo deste estudo foi avaliar a associação dos indicadores antropométricos, de composição

'Departamento de Enfermagem Materno-Infantil e Saúde Pública (EMI), Universidade Federal de Minas Gerais (UFMG) Belo Horizonte, MG, Brasil
Correspondência para:

Gustavo Velásquez-Meléndez Escola de Enfermagem da UFMG Av. Alfredo Balena, 190 - Santa Efigênia

30130-100 - Belo Horizonte, MG Brasil

guveme@ufmg.br

Recebido em 4/Jul/2008

Aceito em 27/Nov/2008 corporal, bioquímicos e hemodinâmicos com a resistência à insulina em duas comunidades rurais. A amostra foi constituída por indivíduos com idade maior ou igual a 18 anos de ambos os sexos. Foram excluídos os diabéticos e as mulheres grávidas. A coleta de dados incluiu variáveis demográficas, de estilo de vida, hemodinâmicas, antropométricas e bioquímicas. Dos 567 participantes, $50,4 \%$ eram homens e $49,6 \%$, mulheres. A maioria das pessoas tinha a cor de pele não-branca $(75,7 \%)$, vivia com seus cônjuges $(69,3 \%)$ e possuía baixo nível educacional. Neste trabalho, $17,4 \%$ das pessoas apresentavam sobrepeso e 5,5\%, obesidade. Pela análise multivariada observou-se que, nos indivíduos adultos, não-diabéticos, com baixo nível socioeconômico e educacional, os fatores associados à resistência à insulina foram o sobrepeso e a obesidade, o aumento da razão cintura/quadril, a proteína C-reativa e a cor de pele. Arq Bras Endocrinol Metab. 2009;53(3):332-9.

Descritores

Sobrepeso; obesidade; composição corporal; resistência à insulina; população rural

\begin{abstract} color. Arq Bras Endocrinol Metab. 2009;53(3):332-9.

Keywords

Overweight; obesity; body composition; insulin resistance; rural population
\end{abstract}

This study explores the relations of anthropometric, body composition assessments, biochemical and hemodynamic parameters with insulin resistance in two rural communities. Sample was composed by adults aged 18 or older, both sexes. Participants were excluded if pregnant and diabetic. Data collection included demographic lifestyle, hemodynamic, anthropometric and biochemical variables. From the 567 subjects, $50.4 \%$ were men and $49.6 \%$, women. Most of the sample was non-white $(75.7 \%)$, lived with partner $(69.3 \%)$ and had low educational level. Overweight and obesity prevalences were $17.4 \%$ and $5.5 \%$, respectively. Multivariate analysis found risk factors associated to insulin resistance for non-diabetic adults with low income and educational level: overweight, obesity, elevated waist-to-hip ratio, C-reactive protein and skin

\section{INTRODUÇÃO}

resistência à insulina pode ser definida como res-
posta diminuída às ações biológicas da insulina (1);
anormalidade que ocorre principalmente em razão de
ação defeituosa da insulina em tecidos periféricos, como
tecidos adiposo, muscular e hepático (2). Essa condi-
ção é considerada fator de risco cardiovascular isolado,
sendo achado comum nos indivíduos com agrupamento
de fatores de risco cardiovascular, aqueles portadores da
síndrome metabólica $(3)$.
Atualmente, alguns trabalhos têm indicado que as comunidades rurais estão incorporando hábitos da vida urbana que contribuem para o desequilíbrio do balanço energético e o ganho de peso corporal. Tais estudos evidenciam também crescimento na proporção de indivíduos com alterações de tolerância à glicose e resistência à insulina $(4,5)$.

Em um estudo realizado no interior de São Paulo, ao comparar áreas urbanas e rurais de dois municípios, as prevalências padronizadas de obesidade foram maiores 
na zona rural em relação à urbana, principalmente para as mulheres. Os autores sugerem que essa alta prevalência de obesidade na zona rural seja decorrente das mudanças no modo de vida dessa população, caracterizando perfil epidemiológico de transição nutricional (6).

O processo de transição nutricional está sendo intensamente estudado desde a década de 1960, principalmente nas áreas urbanas do Brasil (7), entretanto, para as áreas rurais do país são poucas as evidências de que tais mudanças tenham ocorrido, gerando dúvidas se os seus determinantes são os mesmos das áreas urbanas.

Dentro dessa perspectiva, e diante do aumento da prevalência do sobrepeso e da obesidade no meio rural brasileiro, mostrada por recentes pesquisas nacionais, $\mathrm{O}$ objetivo deste estudo foi avaliar a associação dos indicadores antropométricos, de composição corporal, bioquímicos e hemodinâmicos com a resistência à insulina em duas comunidades rurais da região do Vale do Jequitinhonha, MG, Brasil.

\section{MÉTODOS}

Foram realizados estudo de base populacional e delineamento transversal nas comunidades de Virgem das Graças, área rural do município de Ponto dos Volantes, e Caju, área rural do município de Jequitinhonha, ambas localizadas no Vale do Jequitinhonha, MG, Brasil.

As principais atividades econômicas da região são o comércio, a pecuária de corte, a agricultura de subsistência, como a plantação, e o cultivo de mandioca, milho, feijão, arroz, além da fruticultura, dando ênfase principalmete ao plantio de banana. O garimpo e a mineração também são atividades realizadas por algumas pessoas da região.

As comunidades estudadas enfrentam inúmeros problemas, como o baixo nível socioeconômico, a dificuldade de acesso por causa da falta de estrada pavimentada, da elevada taxa de analfabetismo, da qualidade inadequada da água e dos serviços de saúde precários. Nessas áreas rurais as casas são simples, construídas com tijolo de barro e telhas. Muitas casas, apesar de possuírem água encanada de nascentes, ainda utilizam a água dos córregos para realizar atividades que exigem maior consumo, como lavar roupas e vasilhas, uma vez que a água encanada existe em pequena quantidade e várias casas não possuem reservatório. Cabe ressaltar, ainda, que os distritos não possuem rede de esgoto.

Essas comunidades foram escolhidas porque nelas era desenvolvido projeto interinstitucional, e seus morado- res estavam previamente cadastrados por meio de censo. A população-alvo deste estudo constituiu-se de indivíduos com idade maior ou igual a 18 anos, de ambos os sexos e com pelo menos dois anos de residência no local. A população residente nessas comunidades era constituída por 272 famílias, totalizando 1.216 indivíduos. Desse total de indivíduos 522 eram menores de 18 anos, restando 694 indivíduos, para o estudo. Entre esses, houve perda de 100 indivíduos $(14,4 \%)$, reduzindo a amostra para $594(85,6 \%$ do total de indivíduos adultos cadastrados inicialmente), porque 47 não se encontravam no local na época da coleta, 33 mudaram-se para outras localidades e 20 não permitiram a coleta dos dados.

A amostra total, portanto, foi de 594 indivíduos adultos e, desses, foram excluídos ainda 8 pacientes diabéticos e 9 mulheres grávidas. Com isso, a amostra final para esse estudo se constituiu de 567 pessoas com idades entre 18 e 94 anos. Para exclusão dos diabéticos, usaram-se como critério a morbidade autorreferida, o uso de hipoglicemiantes orais e de insulina, além disso, os dados relatados pelos indivíduos foram checados nos prontuários médicos presentes nos centros de saúde dos distritos. Para exclusão das gestantes, o critério foi o relato de a mulher estar grávida.

Os participantes do estudo responderam a um questionário com perguntas relativas aos aspectos sociodemográficos e de estilo de vida. Ao final da entrevista, foi realizada avaliação clínica que consistiu na aferição de medidas antropométricas, de composição corporal, hemodinâmicas e na coleta de sangue para a realização dos exames bioquímicos.

O trabalho de campo foi desenvolvido por seis examinadores previamente treinados, sendo duas nutricionistas e quatro enfermeiros. Para verificar o controle de qualidade dos procedimentos realizados, a concordância entre os examinadores foi avaliada pela ANOVA e pelo teste de Tukey e, também, pelo índice Kappa, com nível de significância de $5 \%(\mathrm{p}<0,05)$. Não foram encontradas diferenças inter e intraexaminadores.

Todas as medidas foram realizadas três vezes, de acordo com recomendações padronizadas (10), sendo o valor final determinado pela média entre elas. $\mathrm{O}$ coordenador dos trabalhos de campo checou a qualidade dos procedimentos realizados ao refazer todos eles em $10 \%$ da amostra que foi escolhida de maneira aleatória.

$\mathrm{O}$ peso foi aferido por meio de balança digital com aproximação de $0,1 \mathrm{~kg}$, estando os participantes vestidos com roupas leves e sem sapatos. A altura foi mensurada por meio de uma fita métrica inextensível, a qual era 
colocada em uma parede sem rodapé à distância de 50 $\mathrm{cm}$ do chão com aproximação de $0,1 \mathrm{~cm}$. Os indivíduos eram posicionados de pé, descalços, olhando para frente, em posição de Frankfurt (arco orbital inferior alinhado em um plano horizontal com o pavilhão auricular), com os pés juntos. A circunferência da cintura (CC) foi medida com fita métrica inelástica, posicionando-a no ponto médio entre a última costela e a parte superior da crista ilíaca. A circunferência do quadril foi mensurada no local de maior proeminência da região glútea. A razão cintura/quadril (RCQ) foi obtida a partir da seguinte equação: RCQ = circunferência da cintura/circunferência do quadril. A circunferência da cintura e a RCQ foram classificadas seguindo recomendações da Organização Mundial da Saúde (OMS), visto que a CC $\geq 94 \mathrm{~cm}$ (homens) $\mathrm{e} \geq 80 \mathrm{~cm}$ (mulheres) foram consideradas como risco de complicações metabólicas aumentado (nível 1), e CC $\geq$ $102 \mathrm{~cm}$ (homens) e $\geq 88 \mathrm{~cm}$ (mulheres) foram consideradas como risco de complicações metabólicas aumentado substancialmente (nível 2); para a RCQ $\geq 1$ para homens e RCQ $\geq 0,85$ para mulheres considerou-se como elevada para risco a doenças cardiovasculares (11).

O índice de massa corporal (IMC) foi calculado de acordo com a fórmula: $\mathrm{IMC}=$ peso $(\mathrm{kg}) / \mathrm{estatura}^{2}(\mathrm{~m})$ e também classificado conforme os pontos de corte estabelecidos pela OMS, sendo: $<18,5\left(\mathrm{~kg} / \mathrm{m}^{2}\right)$ baixo peso, 18,5-24,9 $\left(\mathrm{kg} / \mathrm{m}^{2}\right)$ eutrófico, 25-29,9 $\left(\mathrm{kg} / \mathrm{m}^{2}\right)$ sobrepeso e $\geq 30\left(\mathrm{~kg} / \mathrm{m}^{2}\right)$ obesidade (11).

A análise da composição corporal foi realizada por meio de bioimpedância elétrica com o bioimpedanciômetro Quantum II (RJL Systems ${ }^{\circledR}$, Estados Unidos), de onde foram obtidos os dados referentes ao percentual de gordura corporal. Foi solicitado que os indivíduos estivessem em jejum de 12 horas e vestindo um mínimo de roupas, sem jóias e/ou bijuterias e com a bexiga vazia, conforme protocolo preconizado. Os pontos de corte estabelecidos para verificação do excesso de gordura corporal, de acordo com o sexo, foram percentual de gordura corporal acima de $30,0 \%$ para as mulheres e acima de 20,0\% para os homens (12).

A aferição da pressão arterial foi realizada seguindo todos os passos preconizados no VII Relatório da Joint National Committee (JNC) (13), que definem a forma correta de aferição indireta desse parâmetro diagnóstico; essa medida também foi realizada por examinadores previamente treinados. Foram considerados hipertensos os indivíduos com pressão arterial sistólica $\geq 140 \mathrm{mmHg}$ e/ ou pressão arterial diastólica $\geq 90 \mathrm{mmHg}$ e/ou em uso de medicação anti-hipertensiva.
Amostras de sangue foram obtidas por meio de punção venosa com o paciente em jejum de 12 horas. Para a dosagem dos lipídeos séricos, insulina e proteína C-reativa (PCR), foi coletada amostra de cerca de $10 \mathrm{~mL}$ de sangue sem anticoagulante (tubo seco). As concentrações do colesterol total, triglicérides e glicose foram determinadas empregando-se o teste enzimático colorimétrico, utilizando o analisador COBAS MIRA PLUS (Roche Diagnostics, Suíça). A concentração da lipoproteína de alta densidade (HDL-c) também foi medida pelo teste enzimático colorimétrico, após precipitação das frações da lipoproteína de baixa densidade (LDL-c) e da lipoproteína de muito baixa densidade (VLDL-c) pelo ácido fosfotúngstico e cloreto de magnésio. Níveis de LDL-c foram calculados por aplicação da equação de Friedwald (8). Para a dosagem da glicemia, utilizou-se tubo fluoretado com cerca de $5 \mathrm{~mL}$ de sangue. $\mathrm{O}$ material coletado foi enviado ao laboratório no mesmo dia da coleta, seguindo as especificações técnicas recomendadas. A glicemia de jejum foi caracterizada de acordo com as recomendações da American Diabetes Association (ADA) (14) e os níveis de triglicérides, colesterol total, HDL-c e LDL-c foram classificados consoante os critérios da III Diretrizes Brasileiras sobre Dislipidemias e Diretriz de Prevenção da Aterosclerose (15). As concentrações de PCR de alta sensibilidade e insulina foram determinadas pelo método imunométrico em fase sólida quimioluminescente usando o analisador IMMULITE 2000 (EURO/DPC Ltda., Reino Unido). Para PCR e insulinemia de jejum, consideraram-se elevados os valores, dessas variáveis, categorizados no $4^{\circ}$ quartil da distribuição e normais os valores no $1^{\circ}, 2^{2}$ e e $3^{\circ}$ quartis. O valor do $4^{\circ}$ quartil da PCR foi de $0,41 \mathrm{mg} / \mathrm{dL}$.

A resistência à insulina foi avaliada pelo método $\mathrm{Ho}^{-}$ meostasis Model Assessment (HOMA-IR) (9) a partir da seguinte equação: HOMA-IR = insulinemia de jejum $(\mathrm{mU} / \mathrm{L}) \times$ glicemia de jejum $(\mathrm{mmol} / \mathrm{L}) / 22,5$. Foram consideradas resistentes à insulina as pessoas com valores de HOMA-IR no 4ํ quartil. Como não há consenso em relação ao valor de corte estabelecido como referência para classificar os resultados do índice HOMA-IR, para essas comunidades, foram consideradas resistentes à insulina as pessoas com os valores de HOMA-IR no $4^{\circ}$ quartil da distribuição dessa variável, porquanto $\mathrm{O}$ valor de corte do quarto quartil dessa população foi de 1,13 . Assim, as pessoas com valores no $1^{\circ}, 2^{\circ}$ e $3^{\circ}$ quartis foram consideradas normais.

Os dados foram processados e analisados utilizando-se o programa Statistical Software for Professional 
(STATA), versão 9.0. Os testes de qui-quadrado e de regressão logística simples foram usados para comparar diferenças nas frequências das variáveis categóricas. A razão de prevalência com intervalo de confiança de 95\% (RP; IC 95\%) foi empregada como medida de associação nas análises bivariadas.

Empregou-se a técnica de regressão logística multivariada passo a passo para avaliar a associação entre as variáveis independentes e a resistência à insulina. As covariáveis que apresentaram significância estatística inferior a $0,20(\mathrm{p} \leq 0,20)$ durante a análise bivariada $\mathrm{e}$ plausibilidade biológica foram consideradas como candidatas ao modelo final. A entrada das variáveis independentes no modelo se deu uma a uma por ordem decrescente de significância estatística, e aquelas que perdiam essa característica foram excluídas. Testaramse também a confusão e a interação entre as variáveis. A força de associação foi avaliada pelo cálculo da $o d d s$ ratio (OR) com IC 95\%. O nível de significância estatística estabelecido nessa etapa foi de $5 \%(\mathrm{p} \leq 0,05)$.

O teste de Hosmer-Lemeshow foi utilizado para verificar o ajuste final do modelo. A análise de resíduos também foi realizada com base, principalmente, nos pontos influenciais e não foram encontradas violações das suposições do modelo de regressão.

Este estudo foi aprovado pelo Comitê de Ética e Pesquisa em Seres Humanos da Universidade Federal de Minas Gerais (UFMG), consoante a Resolução no 196/1996 do Conselho Nacional de Saúde, segundo Parecer ETIC no 144/2004. Todos os participantes foram informados sobre o objetivo da pesquisa e seus direitos como participantes. Além disso, eles assinaram o termo de consentimento livre e esclarecido.

\section{RESULTADOS}

A amostra estudada foi constituída de 567 pessoas, das quais $50,4 \%$ eram homens e $49,6 \%$ eram mulheres. A tabela 1 apresenta as características sociodemográficas de acordo com o sexo das comunidades estudadas. Não houve diferenças em relação à distribuição etária no grupo masculino e feminino. A maioria das pessoas tinha a cor de pele não-branca $(75,7 \%)$ e vivia com seus cônjuges $(69,3 \%)$.

Em relação ao anos de escolaridade, não houve diferença entre os sexos, mas foi possível observar que a maioria das pessoas possuía baixa escolaridade: 40,2\% possuíam um a quatro anos de estudo, 36,3\% eram analfabetas e $23,5 \%$ possuíam cinco ou mais anos de estudo.

\begin{tabular}{|c|c|c|c|c|c|c|}
\hline \multirow{3}{*}{ Variáveis } & \multicolumn{4}{|c|}{ Sexo } & \multirow{2}{*}{\multicolumn{2}{|c|}{ Total }} \\
\hline & \multicolumn{2}{|c|}{ Masculino } & \multicolumn{2}{|c|}{ Feminino } & & \\
\hline & $\mathbf{n}$ & $\%$ & $\mathrm{n}$ & $\%$ & $\mathbf{n}$ & $\%$ \\
\hline \multicolumn{7}{|l|}{ Idade (anos) } \\
\hline $18-29$ & 74 & 25,9 & 77 & 27,4 & 151 & 26,6 \\
\hline $30-39$ & 58 & 20,3 & 57 & 20,3 & 115 & 20,3 \\
\hline $40-49$ & 48 & 16,8 & 46 & 16,3 & 94 & 16,6 \\
\hline $50-59$ & 47 & 16,4 & 37 & 13,2 & 84 & 14,8 \\
\hline$\geq 60$ & 59 & 20,6 & 64 & 22,8 & 123 & 21,7 \\
\hline \multicolumn{7}{|l|}{ Cor de pele* } \\
\hline Branca & 51 & 17,8 & 87 & 31,0 & 138 & 24,3 \\
\hline Não-branca & 235 & 82,2 & 194 & 69,0 & 429 & 75,7 \\
\hline \multicolumn{7}{|c|}{ Estado marital } \\
\hline Com cônjuge & 194 & 67,8 & 199 & 70,8 & 393 & 69,3 \\
\hline Sem cônjuge & 92 & 32,2 & 82 & 29,2 & 174 & 30,7 \\
\hline \multicolumn{7}{|c|}{$\begin{array}{l}\text { Escolaridade } \\
\text { (em anos) }\end{array}$} \\
\hline 0 & 112 & 39,2 & 94 & 33,5 & 206 & 36,3 \\
\hline 1 a 4 & 115 & 40,2 & 113 & 40,2 & 228 & 40,2 \\
\hline$\geq 5$ & 59 & 20,6 & 74 & 26,3 & 133 & 23,5 \\
\hline
\end{tabular}

Fonte: Questionário aplicado às pessoas do estudo.

${ }^{\star} p \leq 0,05$ (teste qui-quadrado); ** $p \leq 0,05$ (regressão logística).

As características antropométricas apresentaram diferenças entre os sexos, visto que houve maior proporção de alterações para o sexo feminino (Tabela 2). Pode-se verificar que $17,4 \%$ das pessoas apresentavam sobrepeso e $5,5 \%$ das pessoas eram obesas. Em relação à CC, $12,5 \%$ da população estudada apresentou risco substancialmente aumentado para complicações metabólicas.

Observou-se que $42,9 \%$ das pessoas eram hipertensas, sem diferenças entre os sexos. Em relação ao metabolismo de lipídeos, as mulheres apresentaram maior proporção de níveis baixos de HDL. Para a PCR também foi observada maior proporção de mulheres com valores elevados ( $4^{\circ}$ quartil). Em relação à glicemia de jejum, não foram encontradas diferenças entre os sexos, entretanto, a proporção de insulinemia de jejum foi maior nas mulheres.

A resistência à insulina estava presente em 17,6\% das pessoas com peso normal, em $41,0 \%$ daquelas classificadas com sobrepeso $(\mathrm{RP}=2,33$; $\mathrm{IC}=1,64-3,29) \mathrm{e}$ em 71,4\% dos obesos ( $R P=4,06 ; \mathrm{IC}=2,92-5,64)$; em $18,6 \%$ das pessoas com RCQ normal e em $42,1 \%$ com RCQ elevada $(\mathrm{RP}=2,26$; IC = 1,67-3,06) (Tabela 3). Para a CC, 16,5\% das pessoas sem obesidade abdominal apresentavam níveis elevados de HOMA-IR, 32,8\% das pessoas classificadas pelo nível $\mathrm{l}(\mathrm{RP}=2,0$; IC $=$ $1,30-3,05)$ e $61,3 \%(\mathrm{RP}=3,72 ; \mathrm{IC}=2,74-5,04)$ clas- 
Tabela 2. Características antropométricas e clínico-laboratoriais de acordo com 0 sexo

\begin{tabular}{|c|c|c|c|c|c|c|}
\hline \multirow{3}{*}{ Variáveis } & \multicolumn{4}{|c|}{ Sexo } & \multirow{2}{*}{\multicolumn{2}{|c|}{ Total }} \\
\hline & \multicolumn{2}{|c|}{ Masculino } & \multicolumn{2}{|c|}{ Feminino } & & \\
\hline & $n$ & $\%$ & $n$ & $\%$ & n & $\%$ \\
\hline \multicolumn{7}{|c|}{ IMC $\left(\mathrm{kg} / \mathrm{m}^{2}\right)^{*}$} \\
\hline Baixo peso & 22 & 7,7 & 25 & 9,0 & 47 & 8,3 \\
\hline Eutrófico & 225 & 78,7 & 164 & 58,7 & 389 & 68,8 \\
\hline Sobrepeso & 33 & 11,5 & 65 & 23,3 & 98 & 17,4 \\
\hline Obesidade & 6 & 2,1 & 25 & 9,0 & 31 & 5,5 \\
\hline \multicolumn{7}{|l|}{$\mathrm{CC}(\mathrm{cm})^{*}$} \\
\hline Normal & 270 & 94,4 & 158 & 56,2 & 428 & 75,5 \\
\hline Nível 1 & 11 & 3,8 & 57 & 20,3 & 68 & 12,0 \\
\hline Nível 2 & 5 & 1,8 & 66 & 23,5 & 71 & 12,5 \\
\hline \multicolumn{7}{|l|}{$\mathrm{RCQ}^{* *}$} \\
\hline Normal & 276 & 96,8 & 155 & 55,4 & 431 & 76,3 \\
\hline Elevada & 9 & 3,2 & 125 & 44,6 & 134 & 23,7 \\
\hline \multicolumn{7}{|l|}{$\% G C * *$} \\
\hline Normal & 264 & 92,0 & 118 & 41,4 & 382 & 66,8 \\
\hline Elevada & 23 & 8,0 & 167 & 58,6 & 190 & 33,2 \\
\hline \multicolumn{7}{|c|}{ Pressão arterial } \\
\hline Normotenso & 167 & 58,4 & 157 & 55,9 & 324 & 57,1 \\
\hline Hipertenso & 119 & 41,6 & 124 & 44,1 & 243 & 42,9 \\
\hline \multicolumn{7}{|c|}{ Colesterol total (mg/dL) } \\
\hline$<200$ & 180 & 68,4 & 163 & 60,6 & 343 & 64,5 \\
\hline$\geq 200$ & 83 & 31,6 & 106 & 39,4 & 189 & 35,5 \\
\hline
\end{tabular}

Triglicérides (mg/dL)

$\begin{array}{lcccccc}<150 & 231 & 87,8 & 221 & 82,2 & 452 & 85,0 \\ \geq 150 & 32 & 12,2 & 48 & 17,8 & 80 & 15,0 \\ \text { LDL-c (mg/dL) } & & & & & & \\ <130 & 181 & 68,8 & 169 & 62,8 & 350 & 66,0 \\ \geq 130 & 82 & 31,2 & 100 & 37,2 & 182 & 34,0\end{array}$

HDL-c $(\mathrm{mg} / \mathrm{dL})^{\star *}$

$\begin{array}{lcccccc}\geq 40 & 179 & 68,1 & 209 & 77,7 & 388 & 72,9 \\ <40 & 84 & 31,9 & 60 & 22,3 & 144 & 27,1 \\ \text { PCR (mg/dL) ** } & & & & & & \\ <4^{0} \text { quartil } & 204 & 85,0 & 165 & 66,8 & 369 & 75,7 \\ \geq 4^{0} \text { quartil } & 36 & 15,0 & 82 & 33,2 & 118 & 24,3\end{array}$

Glicemia de jejum $(\mathrm{mg} / \mathrm{dL})$

$\begin{array}{lcccccc}<100 & 234 & 89,3 & 233 & 89,6 & 467 & 89,4 \\ \geq 100 & 28 & 10,7 & 27 & 10,4 & 55 & 10,6\end{array}$

Insulina de jejum $(\mu \mathrm{U} / \mathrm{mL})^{\text {** }}$

$<4^{\circ}$ quartil

$\geq 4^{\circ}$ quartil

$\begin{array}{llllll}209 & 85,3 & 168 & 65,2 & 377 & 75,0\end{array}$

HOMA-IR**

$\begin{array}{llllll}36 & 14,7 & 90 & 34,8 & 128 & 25,0\end{array}$

$<4^{0}$ quartil

$204 \quad 85,0 \quad 165 \quad 66,8 \quad 369 \quad 75,8$

$\geq 4^{\circ}$ quartil

$\begin{array}{llllll}36 & 15,0 & 82 & 33,2 & 118 & 24,2\end{array}$

${ }^{\star} p \leq 0,05$ (regressão logística); ${ }^{* \star} p \leq 0,05$ (teste qui-quadrado); IMC: índice de massa corporal; CC: circunferência da cintura; RCQ: razão circunferência da cintura/circunferência do quadril; \%GC: percentual de gordura corporal; LDL-C: low-density lipoprotein cholesterol; HDL-c: high-density lipoprotein cholesterol; PCR: proteína C-reativa; HOMA-IR: homeostasis model assesment-insulin resistance. sificadas no nível 2 de CC, esses últimos apresentavam a prevalência de valores elevados de HOMA-IR duas vezes maior em relação às pessoas com CC normal. No que diz respeito à \%GC, $46,3 \%$ das pessoas que apresentavam gordura corporal aumentada eram resistentes à ação da insulina $(\mathrm{RP}=3,16 ; \mathrm{IC}=2,32-4,31)$. Para o metabolismo de lipídeos, apenas os níveis elevados de triglicérides relacionaram-se significativamente com a resistência à insulina $(\mathrm{RP}=1,60 ; \mathrm{p}=0,01)$. A PCR também esteve associada à presença de resistência à insulina de maneira que pessoas com valores elevados de PCR $(\mathrm{RP}=1,69 ; \mathrm{p}=0,001)$ foram mais resistentes à insulina em relação às pessoas que apresentaram valores normais. No que diz respeito à pressão arterial, verificou-se que os hipertensos foram mais resistentes à ação da insulina $(\mathrm{RP}=1,54 ; \mathrm{p}=0,007)$ comparados aos normotensos.

Na tabela 4, são apresentados os resultados da análise multivariada. Observou-se que as variáveis que tiveram associação independente com a resistência à insulina foram o sobrepeso $(\mathrm{OR}=4,69)$, a obesidade $(\mathrm{OR}=23,78)$, os valores elevados de $\mathrm{RCQ}(\mathrm{OR}=2,39)$, a $\operatorname{PCR}(\mathrm{OR}=2,03)$ e a cor de pele branca $(\mathrm{OR}=3,66)$.

\section{DISCUSSÃO}

Neste estudo, foram avaliados preditores potenciais da resistência à insulina, em populações de duas comunidades rurais do Vale do Jequitinhonha. O sobrepeso e a obesidade foram mais frequentes no sexo feminino, sendo, respectivamente, $23,3 \%$ e $9,0 \%$, proporções similares às mostradas na Pesquisa Nacional de Saúde e Nutrição, na qual os índices eram desprezíveis para os homens $(1,74 \%)$ e a obesidade acometia $9,0 \%$ das mulheres da área rural brasileira (16).

Nossos resultados também concordam com os dados da última Pesquisa de Orçamento Familiar - POF (2002-2003), os quais demonstram que, para as mulheres das áreas rurais das diferentes regiões brasileiras, as prevalências de sobrepeso e obesidade foram, respectivamente, $40,7 \%$ e $12,7 \%$ (17).

Em um estudo sobre obesidade realizado em quatro comunidades rurais mexicanas, as mulheres também apresentaram maior prevalência de obesidade $(33,0 \%)$ em relação aos homens $(9,0 \%)(18)$. Em algumas regiões do sul dos Estados Unidos, também se encontrou prevalência mais elevada de obesidade na área rural $(28,9 \%)$ em relação à área urbana $(27,5 \%)$ para as mulheres (19). 


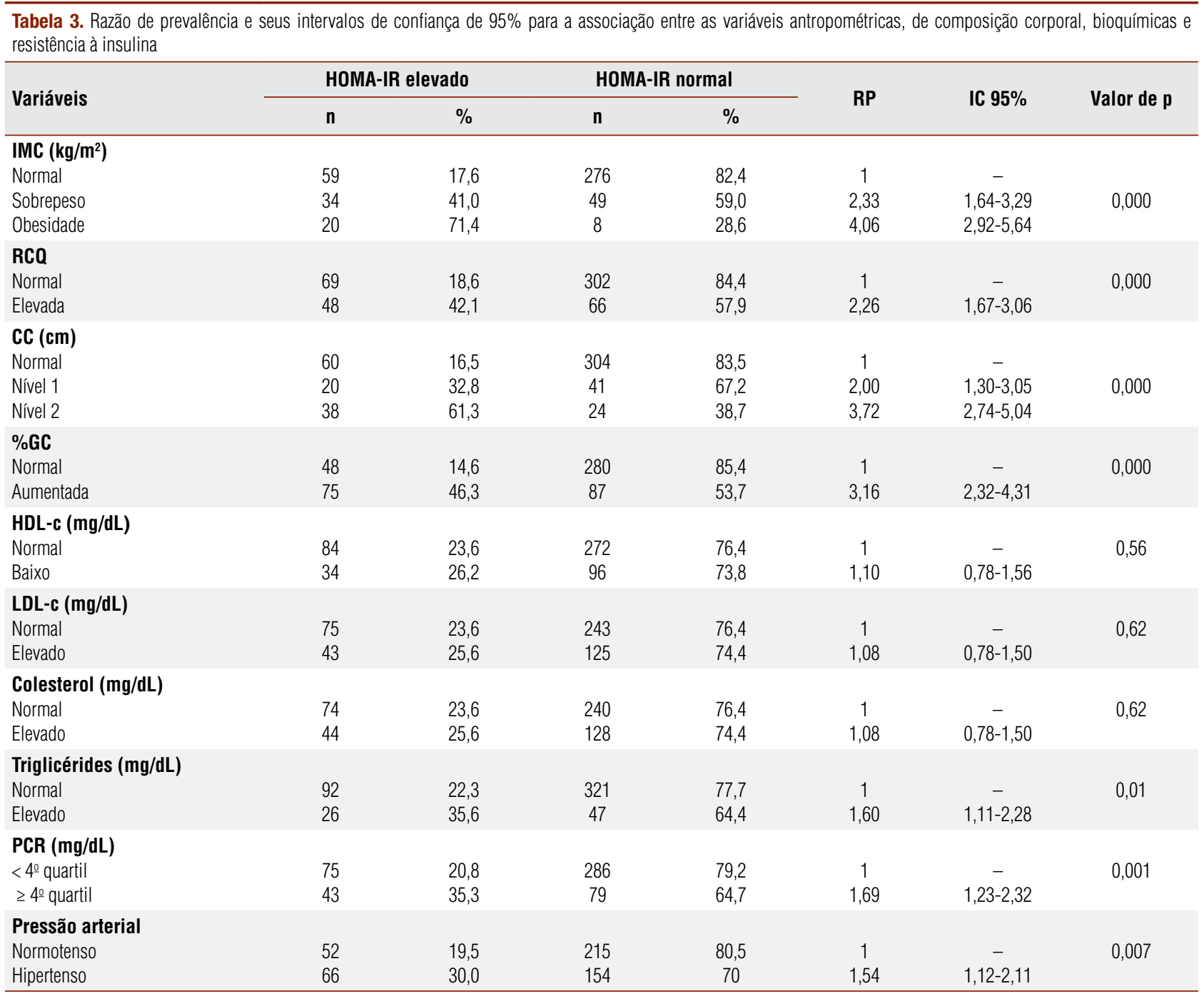

HOMA-IR: homeostasis model assesment-insulin resistance; RP: razão de prevalência; IC: intervalo de confiança; IMC: índice de massa corporal; RCQ: razão circunferência da cintura/circunferência do quadril; CC: circunferência da cintura; \%GC: percentual de gordura corporal; HDL-C: high-density lipoprotein cholesterol; LDL-C: low-density lipoprotein cholesterol; PCR : proteína C-reativa.

Tabela 4. Modelo final de regressão logística tendo a resistência à insulina como variável resposta

\begin{tabular}{lcc}
\hline Variáveis & OR (IC 95\%) & Valor de $\mathbf{p ~}$ \\
\hline IMC $\left.\mathbf{( k g} \mathbf{m}^{\mathbf{2}}\right)$ & 1 (referência) & \\
Eutrofia & $4,69(2,47-8,91)$ & 0,000 \\
Sobrepeso & $23,78(8,29-68,22)$ & 0,000 \\
Obesidade & & \\
RCQ & 1 (referência) & \\
Normal & $2,39(1,30-4,39)$ & 0,005 \\
Elevada & $2,03(1,33-3,10)$ & 0,001 \\
PCR (mg/dL)* & & \\
Cor & 1 (referência) & \\
Não-branca & $3,66(1,99-6,72)$ & 0,000 \\
Branca &
\end{tabular}

Nota: * PCR entrou no modelo como variável contínua.

OR: odds ratio; IMC: índice de massa corporal; RCQ: razão circunferência da cintura/circunferência do quadril; PCR: proteína C-reativa.
No Brasil, em um estudo realizado em dois municípios do interior de São Paulo, a obesidade foi mais prevalente entre as mulheres $(23,4 \%)$ da área rural do que entre os homens $(5,8 \%)$, além disso, nesse mesmo estudo, a prevalência do sobrepeso e da obesidade foi maior na área rural em relação à área urbana, para ambos os sexos (6).

Assim, pode-se perceber que o sobrepeso e a obesidade, antes considerados fenômenos mais presentes no contexto urbano, hoje já acometem populações rurais, afetando, em especial, as mulheres.

Neste estudo, observou-se que a obesidade se manteve fortemente relacionada com a resistência à insulina, inclusive após ajuste por potenciais variáveis de confusão. Esses resultados são sustentados por diversos estu- 
dos que demonstram relação entre o excesso de peso e a resistência à insulina. Em um estudo sobre a distribuição dos valores de HOMA-IR nas diferentes categorias de IMC para a população brasileira, encontrou-se que, para o sobrepeso e a obesidade, os valores de HOMA-IR eram significativamente maiores que para o grupo de pessoas com peso normal (20). Resultados também consolidados por meio de estudos longitudinais demonstram que o ganho de peso está correlacionado positivamente com o aumento dos níveis plasmáticos de insulina e também com a diminuição da sensibilidade à insulina, sugerindo relação entre o aumento do tecido adiposo, a resistência à insulina e a hiperinsulinemia (2l).

Outros achados importantes deste trabalho mostraram que a obesidade abdominal, avaliada tanto pela CC quanto pela RCQ, foi mais frequente nas mulheres $(23,5 \%$ versus $44,6 \%)$ que nos homens ( $1,8 \%$ versus $3,2 \%$ ). Estudos mostram que o acúmulo excessivo de gordura no corpo, principalmente na cavidade abdominal, é determinante fundamental para a resistência à insulina e síndrome metabólica (22-24). Neste estudo a prevalência de resistência à insulina foi maior no grupo de pessoas com alta adiposidade avaliada pelo IMC, pela CC e pela RCQ, e a obesidade abdominal se mostrou como potencial preditor da resistência à insulina, mesmo quando ajustada pelo IMC.

$\mathrm{Na}$ análise multivariada, a PCR manteve a associação com a resistência à insulina confirmada por estudos que mostram que a inflamação crônica subclínica pode ser determinante da resistência à insulina; assim, os níveis de PCR seriam bons marcadores inflamatórios (25). Níveis elevados de PCR são bons marcadores de resistência à insulina e, além disso, a resposta inflamatória aumentada pode levar ao desenvolvimento da resistência à insulina e à hiperinsulinemia compensatória (26). Em um estudo realizado com mulheres de 18 a 60 anos, níveis elevados de PCR foram relacionados com níveis elevados de HOMA-IR, de modo que os valores altos de PCR coincidiam com o quartil mais elevado de HOMA-IR (27).

Outra variável que esteve relacionada, tanto na análise bivariada quanto na análise multivariada com a resistência à insulina, foi a cor da pele. Não existem explicações convincentes para essa relação por causa das distintas cargas genéticas pouco relacionadas ao fenótipo cor de pele. Observa-se em alguns estudos nacionais que essa variável pode não estar relacionada com prevalência de diabetes, que foi $7,8 \%$ nos indivíduos brancos e de $7,3 \%$ em indivíduos de outros grupos raciais, deno- minados não-brancos (28). Entretanto, outros estudos observaram que a relação adiposidade central, resistência à insulina e intolerância à glicose ocorria com maior frequência nas mulheres brancas quando comparadas às negras (29).

Um aspecto limitante das conclusões deste estudo se refere ao desenho do estudo e a potencial confusão residual relativa à não-aferição de variáveis, como os hábitos alimentares e a atividade física das comunidades estudadas.

Os resultados do presente estudo confirmam evidências de alterações no perfil nutricional das comunidades rurais, com taxas de sobrepeso e obesidade similares àquelas encontradas em regiões urbanas do Brasil para as mulheres. As associações entre resistência à insulina, obesidade e PCR encontradas neste estudo podem sugerir o efeito de alterações na composição corporal global sobre alterações do metabolismo dos carboidratos. Portanto, considerando que o diabetes tipo 2 e a obesidade são importantes problemas de saúde pública, políticas de prevenção, promoção e educação em saúde, devem ser empreendidas de maneira efetiva também em áreas rurais, objetivando a melhoria na qualidade e nos hábitos de vida dessas populações.

Apoio financeiro: Fundação de Amparo à Pesquisa de Minas Gerais (Fapemig) e National Institute of Health (NIH).

Declaração: os autores declaram não haver conflitos de interesse científico neste estudo.

\section{REFERÊNCIAS}

1. Geloneze B, Tambascia MA. Avaliação laboratorial e diagnóstico da resistência insulínica. Arq Bras Endocrinol Metab. 2006;50(2):208-15.

2. Reaven GM. Role of insulin resistance in human disease. Diabetes. 1988;37(12):1595-607.

3. Haffner SM. Epidemiology of insulin resistance and its relation to coronary artery disease. Am J Cardiol. 1999;84(1A):11-4.

4. Sayeed MA, Mahtab H, Akter Khanam P, Abdul Latif Z, Keramat Ali SM, Banu A, et al. Diabetes and impaired fasting glycemia in a rural population of Bangladesh. Diabetes Care. 2003;26(4):1034-9.

5. Pérez-Bravo F, Carrasco E, Santos JL, Calvillan M, Larenas G, Albala $\mathrm{C}$. Prevalence of type 2 diabetes and obesity in rural Mapuche population from Chile. Nutrition. 2001;17(3):236-8.

6. Marinho SP, Martins IS, Perestrelo JPP, Oliveira DC. Obesidade em adultos de segmentos pauperizados da sociedade. Rev Nutrição. 2003;16(2):195-201.

7. Mondini L, Monteiro CA. Mudanças no padrão de alimentação na população urbana brasileira (1962-1988). Rev Saude Publica. 1997;28:433-9.

8. Friedewald WT, Levy RI, Fredrickson DS. Estimation of concentrations of low density cholesterol in plasma, without use of the preparative ultracentrifuge. Clin Chem. 1972;18(6):499-502. 
9. Matthews DR, Hosker JP, Rudenski AS, Naylor BA, Treacher DF, Turner RC. Homeostasis model assessment: insulin resistance and beta-cell function from fasting plasma glucose and insulin concentration in man. Diabetologia. 1985;28(7):412-9.

10. Lohman TG, Roche AF, Martorell R. Anthropometric standardization reference manual. Champaign: Human Kinetics Books; 1988.

11. World Health Organization (WHO). Obesity: preventing and managing the global epidemic. Geneva: Report of a WHO Consultation on Obesity; 1998.

12. Abernathy RP, Black DR. Healthy body weights: an alternative perspective. Am J Clin Nutr. 1996;63 Suppl 3:448-51.

13. Chobanian AV, Bakris GL, Black HR, Cushman WC, Green LA, Izzo JL Jr, et al. and Blood Institute Joint National Committee on Prevention, Detection, Evaluation, and Treatment of High Blood Pressure; National High Blood Pressure Education Program Coordinating Committee. The seventh report of the Joint National Committee on detection, evaluation, and treatment of high blood pressure: the JNC 7 report. JAMA. 2003;289(19):2560-72.

14. American Diabetes Association (ADA). Diagnosis and classification of diabetes mellitus. Diabetes Care. 2004;27 Suppl 1:5-10.

15. Sociedade Brasileira de Cardiologia (SBC). III Diretrizes Brasileiras sobre Dislipidemias e Diretriz de Prevenção da Aterosclerose do Departamento de Aterosclerose da Sociedade Brasileira de Cardiologia. Arq Bras Cardiol. 2001;77 Suppl 3:1-48.

16. Coitinho DC, Leão MM, Recine E, Sichieri R. Condições nutricionais da população brasileira: adultos e idosos. Brasília: Ministério da Saúde; 1991.

17. Instituto Brasileiro de Geografia e Estatística (IBGE). Pesquisa de orçamentos familiares 2002-2003: análise da disponibilidade domiciliar de alimentos e do estado nutricional no Brasil. Rio de Janeiro: IBGE; 2004.

18. Sánchez-Castillo CP, Lara JJ, Villa AR, Aguirre J, Escobar M, Gutiérrez $\mathrm{H}$, et al. Unusually high prevalence rates of obesity in four Mexican rural communities. Euro J Clin Nutrit. 2001;55(10):833-40.

19. Ramsey PW, Glenn LL. Obesity and health status in rural, urban, and suburban southern women. Southern Med J. 2002;95(7):666-71.
20. Ghiringhello MT, Vieira JGH, Tachibana TT, Ferrer C, Maciel RMB, Amioka PHC, et al. Distribution of HOMA-IR in Brazilian subjects with different body mass indexes. Arq Bras Endocrinol Metab. 2006;50(3):573-4.

21. Gould AJ, Williams DEM, Byrne CD, Hales CN, Wareham NJ. Prospective cohort study of the relationship of markers of insulin resistance and secretion with weight gain and changes in regional adiposity. Int J Obes. 1999;23(12):1256-61.

22. Lee KU. Oxidative stress markers in Korean subjetcs with insulin resistance syndrome. Diabetes Res Clin Pract. 2001;54 Suppl 2:29-33.

23. Carey VJ, Walters EE, Colditz GA, Solomon CG, WillettWC, Rosner $B A$, et al. Body fat distribution and risk of non-insulin-dependent diabetes mellitus in women. The Nurses' Health Study. Am J Epidemiol. 1997;145(7):614-9.

24. Mckeigue PM, Shah B, Marmot MG. Relation of central obesity and insulin resistance with high diabetes prevalence and cardiovascular risk in South Asians. Lancet. 1991;337(8738):382-6.

25. Rosenbaum P, Ferreira SRG. Uma atualização em risco cardiovascular da síndrome metabólica. Arq Bras Endocrinol Metab. 2003;47(3):220-7.

26. Fröhlich M, Imhof A, Berg G, Hutchinson WL, Pepys MB, Boeing $\mathrm{H}$, et al. Association between $\mathrm{C}$-reactive protein and features of the metabolic syndrome: a population-based study. Diabetes Care. 2000;23(12):1835-9.

27. Pannacciulli N, Cantatore FP, Minenna A, Bellacicco M, Giorgino $R$, De Pergola G. C-reactive protein is independently associated with total body fat, central fat, and insulin resistance in adult women. Int J Obes. 2001;25(10):1416-20.

28. Malerbi DA, Franco LJ. Multicenter study of the prevalence of diabetes mellitus and impaired glucose tolerance in the urban Brazilian population aged 30-69 yr. Diabetes Care. 1992;15(11):1509-16.

29. Dowling HJ, Fried SK, Pi-Sunyer FX. Insulin resistance in adipocytes of obese women: effects of body fat distribution and race. Metabolism. 1995;44(8):987-95. 